\title{
An evaluation index of path quantization based on entropy weight method
}

\author{
Mao $\mathrm{Ji}^{1, \text { a }}$ \\ ${ }^{1}$ North China Electric Power University (Baoding), Baoding 071000, China; \\ aleyu11@outlook.com
}

Keywords: Entropy weight method, Risk coefficient, Refugee migration

\begin{abstract}
The traditional optimal path is the shortest route, obviously, if condition of each path is different, this method has certain disadvantages. This paper presents a new method of selecting the optimal path with the background of refugee migration in the Middle East. the traditional optimal path is the shortest path variable the new method considers different factors of each path, and put forward a new index called the risk coefficient, RC, to describe danger degree of each path. And the article finally worked out the risk factors of the migration routes for refugees with the Matlab.
\end{abstract}

\section{Introduction}

In real life, the problem of selecting the optimal route is often encountered, and the general optimal route is the shortest route. However, mostly because of the different conditions of each route, the shortest path is not necessarily the optimal path. In this paper, a new method considering a variety of factors of selection to the optimal path is been improved with the current hot issue of refugee migration in the Middle East as the background.

Events in the Middle East have caused a massive surge of refugees emigrating from the Middle East into safe haven countries in Europe and parts of Asia, often moving through the Mediterranean and into countries such as Turkey, Hungary, Germany, France, and UK. More than a million migrants and refugees crossed into Europe in 2015, sparking a crisis as countries struggle to cope with the influx, and creating division in the EU over how best to deal with resettling people [1]. On the other hand, there are multiple routes for the refugees from the Middle East to different destination. Each route has different levels of safety and accessibility. Thus, it is vital to develop a better understanding of the factors involved with facilitating the movement of refugees from their countries of origin into safe-haven countries.

\section{The Theory and Application of Entropy Weight Method}

Entropy weight method is a kind of objective weighting method. It can use information entropy to calculate the entropy weight of every index according to the degree of variation of each index. Then, it can modify every index through entropy weight. Thus, the final weight index is more objective.

In the calculation of entropy weight method, the importance of the comprehensive index and the information provided by the indicators are often used to determine the final weight of each index. When there are $m$ evaluation projects and $n$ evaluation indicators, the formation of the original matrix is as follows:

$$
R=\left[\begin{array}{cccc}
r_{11} & r_{12} & \ldots & r_{1 n} \\
r_{21} & r_{22} & \ldots & r_{2 n} \\
\ldots & \ldots & \ldots & \ldots \\
r_{m 1} & r_{m 2} & \ldots & r_{n n}
\end{array}\right]_{m^{*} n}
$$

In this model, $r_{i j}$ means the numerical value of the $i$ route, $j$ index. For example, $r_{12}$ means the second indicators (temperature) of the first route (from Morocco to Spain).The calculation procedure of entropy weight method is as follows: 
1) Specific gravity $p_{i j}$ of the $i$ project in the $j$ indicators can be obtained using the equation (2):

$$
p_{i j}=\left(r_{i j}-\min \left(r_{i}\right)\right) /\left(\max \left(r_{i}\right)-\min \left(r_{i}\right)\right)
$$

2) Then, the entropy of each index $e_{j}$ can be calculated by equation (3):

$$
e_{j}=-k \sum_{i=1}^{m} p_{i j} * \ln p_{i j}
$$

3) In the end, the entropy weight of every index can be obtained.

$$
w_{j}=\left(1-e_{j}\right) /\left(\sum_{j=1}^{n}\left(1-e_{j}\right)\right)
$$

When the value of each alternative is exactly the same on the index $j$, the entropy of the index reaches the maximum value of 1 and the entropy weight is 0 . This indicates that the index could not provide useful information to the decision makers. In this case, all the alternatives are not different for the decision maker. Therefore, the entropy weight is not the coefficient of the importance of the index, but the index of the evaluation object.

\section{Calculation of RC of Each Route}

\begin{tabular}{|c|c|c|}
\hline & Parameters needed in PLP & Parameters needed in STS \\
\hline The origin & the number of refugees & \multirow{3}{*}{$\begin{array}{l}\text { wind, temperature, } \\
\text { the distance, GDP, } \\
\text { unemployment rate, } \\
\text { population density and traffic } \\
\text { mode }\end{array}$} \\
\hline The route & $\begin{array}{l}\text { the wind, ocean currents, } \\
\text { temperature, the occurrence } \\
\text { probability of bad weather } \\
\text { and etc. }\end{array}$ & \\
\hline $\begin{array}{c}\text { The } \\
\text { destination }\end{array}$ & $\begin{array}{l}\text { the distance, GDP, } \\
\text { unemployment rate } \\
\text { population density }\end{array}$ & \\
\hline
\end{tabular}

Table 1 lists the parameters required in the PLP and STS two models.

Tab 1.parameters in the PLP and STS models

As is shown in Tab 1, parameters needed in the PLP model are more than them in the STS model. However, the use of fewer parameters do not mean that is not accurate. The feasibility proof of the alternative is given below.

The number of refugees is used in the step 2 to plan the allocation of refugees. As for the ocean current, in the Atlantic Ocean in open sea near the European continental the speed of ocean current is about $0.9 \mathrm{~km} / \mathrm{h}$ [2]. It has little effect to the navigation of the ship especially inside the Mediterranean. And on the other hand, occurrence frequency of ocean currents and its velocity are affected by seasonal factors. While refugee migration motivation has nothing to do with the season. Therefore, the ocean current can be ignored. In addition, the Mediterranean region is less likely to extreme weather outbreak [3]. The analysis is not a long-term refugee migration. Therefore, the occurrence probability of bad weather can be ignored.

Frequently selected migration routes by refugees can be found in literatures [4], we use the data collected [5], combine with the entropy method, and get the risk coefficient of each route finally.

Figure 1 shows the migration routes of the refugees, where the red lines are the actual migration routes mentioned in the literature, and the black lines are simplified routes used in the model. 


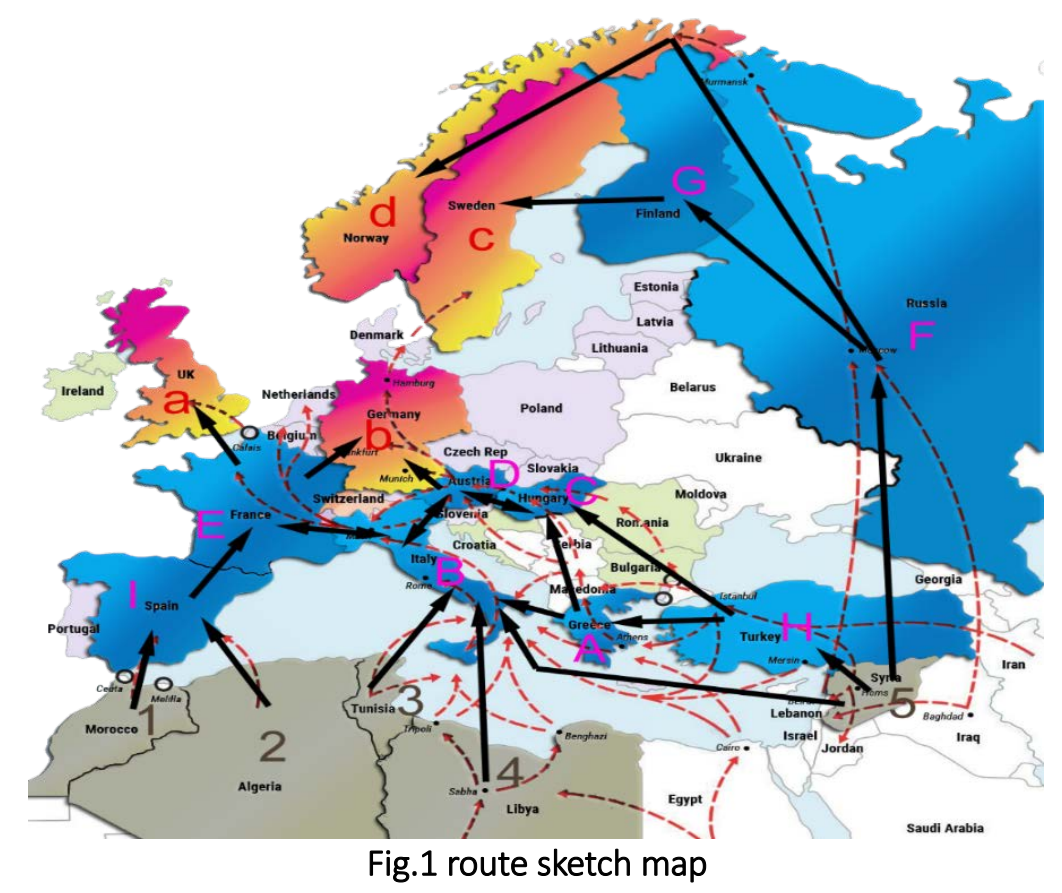

In the figure above, the numbers represent the starting state of the refugees, the capital letters indicate the transit country on the way, and the lower case letters represent the final destination.

The matrix $R^{\prime}$ can be obtained with the standardized of matrix $R$. And the weight of every index $w_{j}$ can be got by the formula (4).

The rick coefficient can be calculated as the following equation:

$$
R C=R^{\prime} \cdot w^{T}
$$

And the results of the risk coefficients of each route are shown in the figure 2.

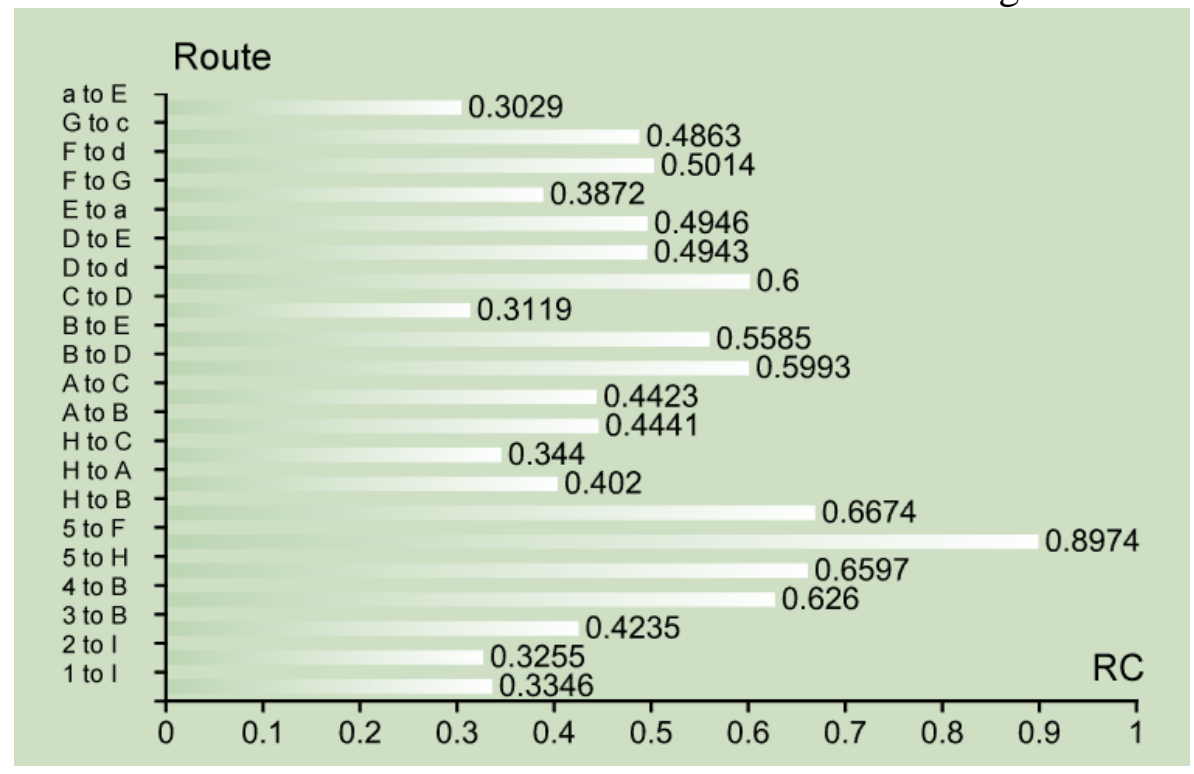

Fig. 2 the risk coefficients of each route

\section{Summary}

Three aspects are involved in the refugee migration: origins, routes and destinations. In this article, the factors of the route can be evaluated as an indicator for the purpose of combining with the destination and the origin. And this evaluation index called the risk coefficient, $R C$, can be acquired according to the quantitative results with entropy weight method.

As is shown to us in the figure2, the risk coefficient of the routes from the Syria is higher generally. It is consistent with the actual situation in Syria domestic environmental turbulence [6]. That is to say, the model is accurate in a certain degree. 


\section{Reference}

[1]Information on: http://www.bbc.com/news/world-europe-34131911

[2]Information on: http://baike.baidu.com/link?url=FdYa0vU5sZHK52_FR-yluIfSPct

[3]Information on: https://en.wikipedia.org/wiki/Mediterranean_climate

[4]Information on: http://www.bbc.com/news/world-europe-34131911

[5]Information on: http://missingmigrants.iom.int/

[6]Information on: http://www.bbc.com/news/world-middle-east-17258397 